\title{
Gamma Knife surgery for facial nerve schwannomas
}

\author{
Clinical article
}

\author{
Ju Hyung Moon, M.D., ${ }^{1,3}$ Won Seok Chang, M.D., ${ }^{1,2,4}$ Hyun Ho Jung, M.D., ${ }^{1,2,4}$ \\ Kyu Sung Lee, M.D., Ph.D., ${ }^{1,3,4}$ Yong Gou Park, M.D., Ph.D., ${ }^{1,2,4}$ \\ and Jong Hee Chang, M.D., Ph.D. ${ }^{1-4}$ \\ ${ }^{1}$ Department of Neurosurgery, ${ }^{2}$ Gamma Knife Center, ${ }^{3}$ Brain Tumor Center, and ${ }^{4}$ Brain Research Institute, \\ Yonsei University Health System, Seoul, Republic of Korea
}

\begin{abstract}
Object. The aim of this study was to evaluate the tumor control rate and functional outcomes after Gamma Knife surgery (GKS) among patients with a facial nerve schwannoma.

Methods. The authors reviewed the radiological data and clinical records for 14 patients who had consecutively undergone GKS for a facial nerve schwannoma. Before GKS, 12 patients had facial palsy, 7 patients had hearing disturbance, and 5 patients had undergone partial or subtotal tumor resection. The mean and median tumor volumes were $3707 \mathrm{~mm}^{3}$ and $3000 \mathrm{~mm}^{3}$, respectively (range $117-10,100 \mathrm{~mm}^{3}$ ). The mean tumor margin dose was $13.2 \mathrm{~Gy}$ (range 12-15 Gy), and the mean maximum tumor dose was 26.4 Gy (range 24-30 Gy). The mean follow-up period was 80.7 months (range $2-170$ months).

Results. Control of tumor growth was achieved in all $12(100 \%)$ patients who were followed up for longer than 2 years. After GKS, facial nerve function improved in 2 patients, remained unchanged in 9 patients, and worsened in 3 patients. All patients who had had serviceable hearing at the preliminary examination maintained their hearing at a useful level after GKS. Other than mild tinnitus reported by 3 patients, no other major complications developed.

Conclusions. GKS for facial nerve schwannomas resulted in excellent tumor control rates and functional outcomes. GKS might be a good primary treatment option for patients with a small- to medium-sized facial nerve schwannoma when facial nerve function and hearing are relatively preserved. (http://thejns.org/doi/abs/10.3171/2014.8.GKS141504)
\end{abstract}

\section{KEY WoRds • Gamma Knife surgery • radiosurgery • facial nerve • schwannoma $\quad$ stereotactic radiosurgery}

$\mathrm{S}$ CHWANNOMAS are benign tumors that arise from the Schwann cells of the nerve sheath; they account for about $10 \%$ of all primary brain tumors. More than $90 \%$ of intracranial schwannomas are vestibular. ${ }^{8,30} \mathrm{Fa}-$ cial nerve schwannomas are in the minority, even among nonvestibular schwannomas; facial nerve schwannomas account for less than $2 \%$ of all intracranial schwannomas and less than $1 \%$ of intrapetrous tumors. ${ }^{31,32}$ Facial nerve schwannomas can occur along any segment of the nerve, often involving multiple segments; they have a predilection for the geniculate ganglion and the labyrinthine, tympanic, and mastoid segments. $2,22,24,28,31$ The diversity of tumor locations results in variable symptoms, including facial palsy, hearing loss, tinnitus, otalgia, hemifacial spasm, and vestibular symptoms. ${ }^{2,22,31}$ Because of the rarity of facial schwannomas and the variety of their clinical presentations, there is no universal consensus on an optimal management strategy. ${ }^{1}$ Many consider excision with

Abbreviations used in this paper: GKS = Gamma Knife surgery; $\mathrm{HB}=$ House-Brackmann; SRS = stereotactic radiosurgery. nerve grafting to be the primary treatment, but this procedure cannot guarantee either maintenance of vestibulocochlear function or recovery of the facial nerve function to greater than House-Brackmann (HB) Grade III. 5,22,33 Accordingly, observation with regular follow-up imaging is advocated for patients with good facial nerve fuction. ${ }^{17,23}$ Because the vestibulocochlear and facial neuropathy associated with excision could affect patients both functionally and emotionally, various therapeutic options have been proposed to maximize facial and vestibulocochlear nerve fuction. ${ }^{1,33}$ Stereotactic radiosurgery (SRS) is known to be safe and effective for the management of vestibular schwannomas; $;^{7,13,18}$ this modality has therefore emerged as a primary therapeutic option for controlling facial nerve schwannomas while preserving function of the cranial nerves. However, to our knowledge, there are few reports concerning the safety and efficacy of radiosurgery for facial nerve schwannomas, and data regarding long-term follow-up are limited. ${ }^{9-11,16,19,20,27,33} \mathrm{We}$ analyzed long-term tumor control and functional outcomes from a series of patients treated with GKS for both newly diagnosed and residual facial nerve schwannoma. 


\section{Methods}

Since 2000, a total of 14 patients with a facial nerve schwannoma have undergone GKS at Severance Hospital, Yonsei University College of Medicine, in Seoul. Of these 14 patients, 6 were male and 8 were female and ages ranged from 17 to 63 years (mean 36.9 years). For 5 patients, partial or subtotal tumor resection had been previously performed, and diagnosis was confirmed by microsurgical observation. For the other 9 patients, the diagnosis was based on imaging findings and neurological signs. Neurological evaluation for facial nerve function and hearing was performed by using the HB grading system and the GardnerRobertson classification, respectively. At the time of GKS, facial palsy was classified as HB Grade I for 2 patients, Grade II for 7 patients, Grade III for 2 patients, Grade IV for 1 patient, Grade V for 1 patient, and Grade VI for 1 patient. Hearing was graded as Gardner-Robertson Class I for 7 patients, Class II for 1 patient, Class III for 2 patients, and Class V for 4 patients. Of the 5 patients who underwent partial or subtotal resection before GKS, 1 patient experienced decreased facial nerve function and hearing and 3 patients experienced a significant reduction in hearing after surgery. Symptoms other than facial motor function and hearing reduction included tinnitus, hemifacial spasm, facial numbness, lacrimation, dizziness, otalgia, decreased taste, diplopia, and seizure. Neoplasms were located in various segments of the facial nerve and in most patients involved multiple segments. Most tumors involved the geniculate segment (10 patients; 71.4\%), followed in frequency by the labyrinthine segment ( 7 patients; $50 \%)$, the internal auditory canal (7 patients; $50 \%$ ), the cerebellopontine angle (7 patients; $50 \%$ ), the tympanic segment (5 patients; $35.7 \%$ ), and the mastoid segment (3 patients; $21.4 \%$ ). Mean and median tumor volumes were $3707 \mathrm{~mm}^{3}$ and 3000 $\mathrm{mm}^{3}$, respectively (range $117-10,100 \mathrm{~mm}^{3}$ ) (Table 1).

Based on T1-weighted Gd-enhanced MRI and on T2-weighted MRI, GKS was performed using the Leksell Gamma Knife model B, C, or Perfexion (Elekta AB). GammaPlan software (Elekta AB) was used for dose planning. The mean tumor margin dose, set as the 50\% isodose line, was 13.2 Gy (range 12-15 Gy), and the mean maximum tumor dose was 26.4 Gy (range 24-30 Gy). After GKS, patients were evaluated with regularly scheduled imaging and clinical assessments.

\section{Results}

The mean radiological and clinical follow-up period was 80.7 months (range $2-170$ months). Follow-up lasted longer than 2 years for $12(86 \%)$ patients, among whom 9 $(64 \%)$ have been followed up for longer than 5 years and $4(29 \%)$ for longer than 10 years.

\section{Tumor Control}

Of the 13 patients who were followed up for longer than 6 months, the 6-month follow-up images showed tumor enlargement in 6 patients, tumor stability in 3 patients, and tumor regression in 4 patients. Of the 12 patients who were followed up for longer than 2 years, the last follow-up images showed tumor regression in 7 patients and tumor stability in 5 patients; no tumor enlargement was found in any patient (Figs. 1 and 2). Of the 6 patients for whom tumor enlargement was seen at 6 months, tumor regression was seen on the last follow-up images for 5 patients (Fig. 3 ), and 1 patient was not evaluated because the total followup duration was less than 1 year. One patient in the study group was not evaluated after GKS because the postradiosurgical period was less than 6 months. Tumor control was achieved in all $12(100 \%)$ patients who had been followed up for longer than 2 years (Table 2).

\section{Functional Outcomes}

After GKS, facial nerve function improved in 2 patients and worsened in 3 patients. An improvement in facial palsy, from HB Grade III to Grade II, was observed in one patient, and a remarkable improvement, from HB Grade V to Grade II, was observed in another patient. Soon after GKS, facial nerve function worsened in 3 patients, from HB Grade II to Grade IV. For all 3 patients with deteriorated facial nerve function, MRI performed at 6 months after GKS showed tumor expansion and a loss of central enhancement. For the other 9 patients, facial nerve function remained unchanged after GKS.

Hearing function generally remained unchanged. Hearing worsened in 1 patient, but the overall function was still serviceable. All patients who had had serviceable hearing at the preliminary examination maintained hearing at useful levels after GKS. No other major complications occurred, although 3 patients reported mild tinnitus (Table 3; Fig. 4).

\section{Discussion}

Facial nerve schwannomas are rare, benign tumors that can originate anywhere along the course of cranial nerve VII. Although advances in imaging techniques have made diagnosis and identification of tumor origin much easier, it can still be difficult to distinguish facial nerve schwannomas from other neoplasms, such as vestibular schwannomas and meningiomas, located in the cerebellopontine angle and the petrous area of the temporal bone. A good indicator suggestive of facial nerve schwannoma is involvement of the geniculate ganglion or the labyrinthine, tympanic, or mastoid segment of the facial nerve; an additional clue can be the presence of primary symptoms associated with facial nerve function, including progressive or repetitive hemifacial weakness. However, when they occur in the internal auditory canal or at the cerebellopontine angle, facial nerve schwannomas are often impossible to distinguish from vestibular schwannomas. ${ }^{4,21}$ In the series reported here, the preoperative diagnosis was preferentially based on MR imaging. For most patients, the geniculate ganglion or the labyrinthine segment was involved, and for 2 patients, disease was restricted to the cerebellopontine angle and the internal auditory canal. For these 2 patients whose tumors were impossible to distinguish from vestibular schwannomas, the diagnoses were confirmed by microsurgical observation. For $12(85.7 \%)$ patients, the presence of facial weakness, with or without hearing loss, helped with diagnosis. 
TABLE 1: Characteristics of the 14 patients who underwent GKS for facial nerve schwannomas*

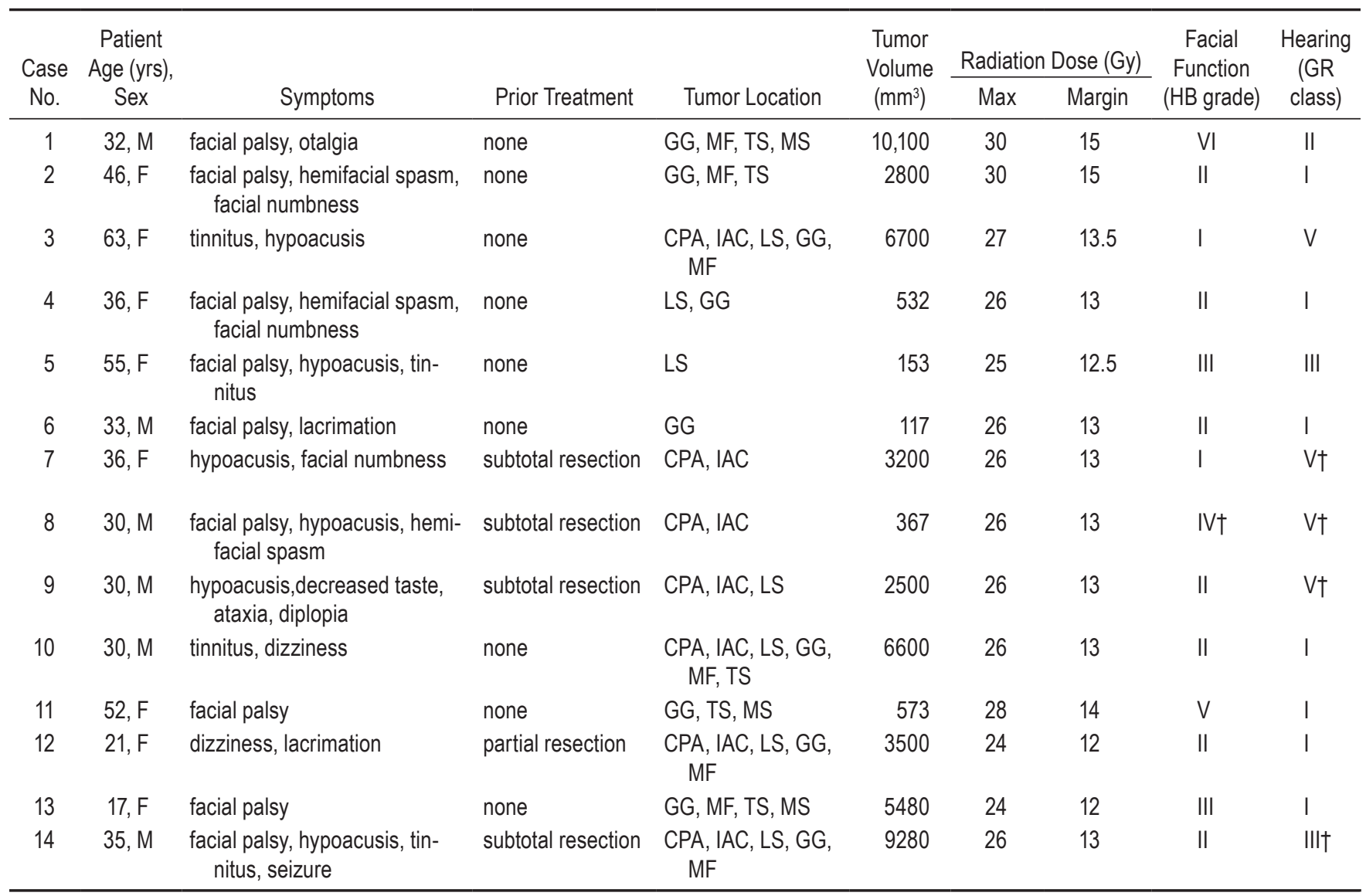

* $\mathrm{CPA}=$ cerebellopontine angle; $\mathrm{GG}=$ geniculate ganglion; $\mathrm{GR}=$ Gardner-Robertson; $\mathrm{IAC}=$ internal auditory canal; $\mathrm{LS}=$ labyrinthine segment; MF = middle cranial fossa; $M S$ = mastoid segment; TS = tympanic segment.

$\dagger$ Postoperative effects.

Management strategies for patients with facial nerve schwannomas include observation, resection, and radiosurgery. Traditionally, complete excision with facial nerve reconstruction had been considered the treatment of choice. Because most tumors engulf the facial nerve, it is almost inevitably sacrificed during surgery; facial nerve reconstruction, by use of end-to-end anastomosis or nerve grafting, is usually necessary. For patients who undergo tumor excision with nerve reconstruction, postoperative facial palsies unavoidably develop, and most patients do not recover facial nerve function better than HB Grade III. ${ }^{6,10,33}$ Therefore, approaches that favor facial nerve preservation, such as observation, partial or subtotal removal, bony decompression, fascicle preservation surgery, and SRS, are advocated for patients who have good facial nerve function before treatment. ${ }^{1,33}$ Observation could be a good management option, particularly for elderly patients or those with severe concurrent medical conditions, ${ }^{17}$ but interven-
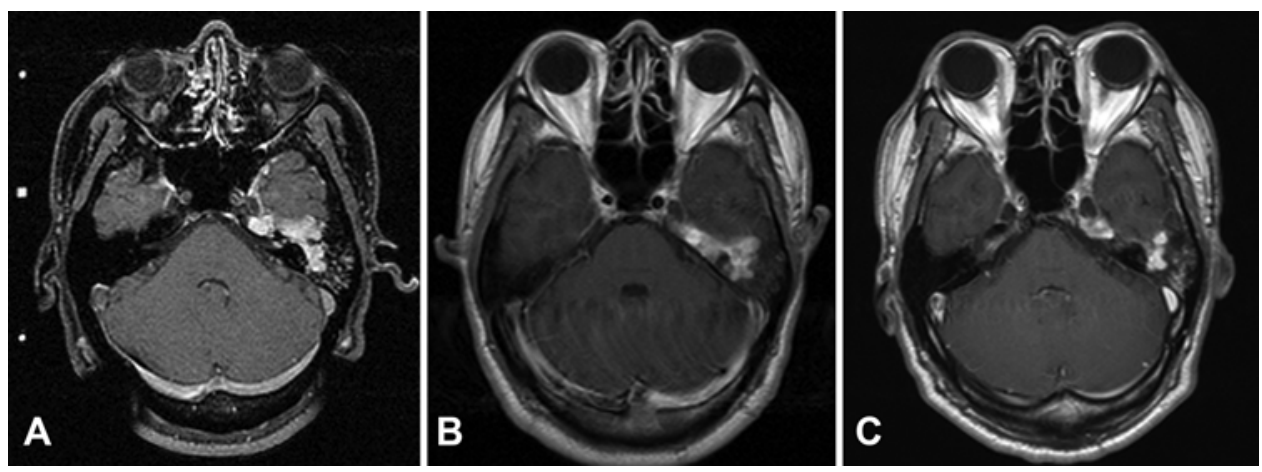

FIG. 1. Case 1. Axial T1-weighted contrast-enhanced MR images obtained before GKS (A), 6 months after GKS (B), and 168 months after GKS (C), demonstrating remarkable shrinkage of facial nerve schwannoma. 

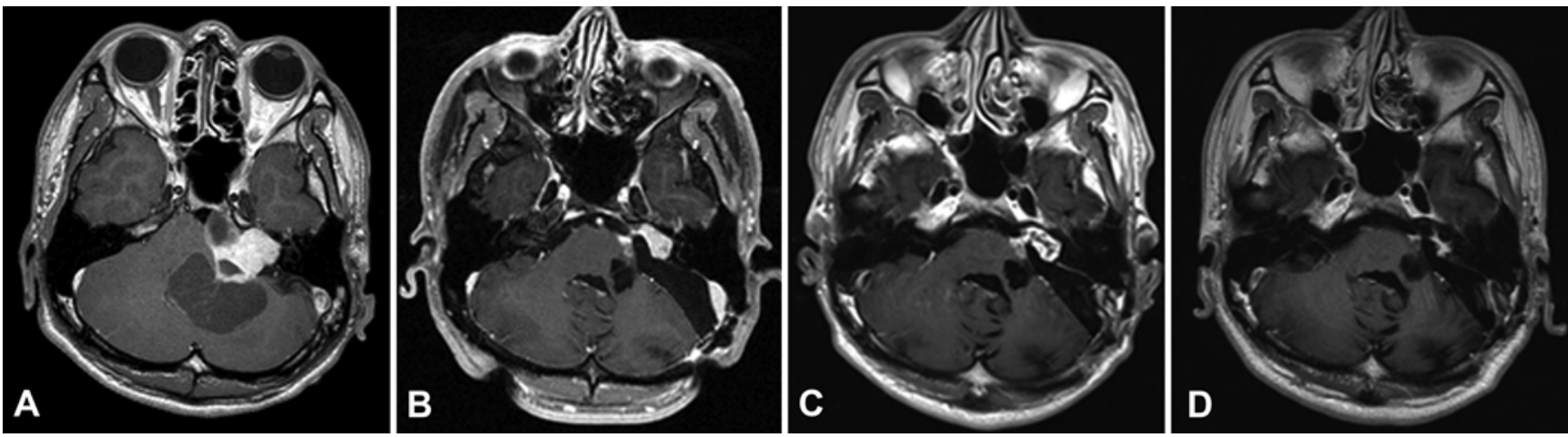

FIG. 2. Case 9. Axial T1-weighted contrast-enhanced MR images obtained before subtotal resection (A), before GKS (B), 6 months after GKS (C), and 48 months after GKS (D). Central low intensity with stable size was noted 6 months after GKS, and remarkable shrinkage of tumor was noted 48 months after GKS.
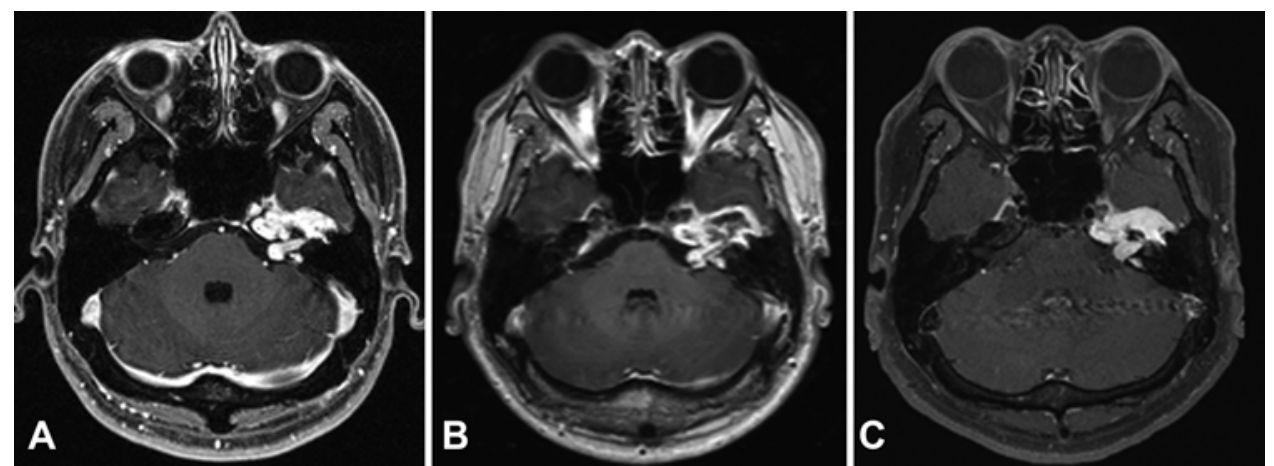

Fig. 3. Case 10. Axial T1-weighted contrast-enhanced MR images obtained before (A), 6 months after (B), and 48 months after (C) GKS. Transient tumor expansion with central low intensity was noted 6 months after GKS, and tumor regression to preradiosurgical size and maintenance at a stable size were noted 48 months after GKS.

TABLE 2: Summary of imaging changes after GKS*

\begin{tabular}{ccccc}
\hline & \multicolumn{3}{c}{ Initial Tumor Volume } & \\
\cline { 2 - 3 } Case No. & Initial $\left(\mathrm{mm}^{3}\right)$ & At 6 Mos & At Last Follow-Up & Follow-Up (mos) \\
\hline 1 & 10,100 & decreased & decreased & 170 \\
2 & 2800 & increased & stable & 166 \\
3 & 6700 & decreased & decreased & 127 \\
4 & 532 & increased & stable & 125 \\
5 & 153 & stable & decreased & 99 \\
6 & 117 & decreased & decreased & 96 \\
7 & 3200 & decreased & decreased & 77 \\
8 & 367 & stable & stable & 72 \\
9 & 2500 & stable & decreased & 67 \\
10 & 6600 & increased & stable & 51 \\
11 & 573 & increased & decreased & 40 \\
12 & 3500 & increased & stable & 32 \\
14 & 5480 & increased & NP & 6 \\
\hline
\end{tabular}

* NP = follow-up imaging not performed because of the short follow-up periods. 
TABLE 3: Summary of functional and clinical results after GKS

\begin{tabular}{|c|c|c|c|c|c|c|}
\hline \multirow[b]{2}{*}{ Case No. } & \multicolumn{2}{|c|}{ Facial Nerve Function (HB grade) } & \multicolumn{2}{|c|}{ Hearing Function (GR class) } & \multirow[b]{2}{*}{ New Symptoms } & \multirow[b]{2}{*}{ Follow-Up (mos) } \\
\hline & Before GKS & After GKS & Before GKS & After GKS & & \\
\hline 1 & VI & VI & ॥ & II & none & 170 \\
\hline 2 & $\|$ & IV & I & $\|$ & tinnitus & 166 \\
\hline 3 & I & I & V & V & none & 127 \\
\hline 4 & $\|$ & IV & I & I & tinnitus & 125 \\
\hline 5 & III & $\|$ & III & III & none & 99 \\
\hline 6 & $\|$ & $\|$ & I & I & none & 96 \\
\hline 7 & I & I & V & V & none & 77 \\
\hline 8 & IV & IV & V & V & none & 72 \\
\hline 9 & II & II & V & V & none & 67 \\
\hline 10 & II & IV & I & I & none & 51 \\
\hline 11 & V & II & 1 & I & none & 40 \\
\hline 12 & II & II & 1 & I & tinnitus & 32 \\
\hline 13 & III & III & 1 & I & none & 6 \\
\hline 14 & $\|$ & $\|$ & III & III & none & 2 \\
\hline
\end{tabular}

tion must be considered for patients who experience tumor growth or symptom development. For most patients, partial or subtotal removal yields better facial nerve outcomes than does total removal with nerve grafting, ${ }^{23,25,29}$ but the longterm risk for recurrence is high..$^{15}$ Bony decompression of the facial canal to reduce interfascicular pressure can help improve facial nerve function, but patients need to be assessed regularly for tumor growth. ${ }^{22}$ Fascicle preservation surgery that spares the main trunk of the facial nerve is limited to eccentrically growing tumors that involve only a small proportion of nerve fibers; this treatment still carries the risk for damage to the facial nerve..$^{14,26}$

Because SRS for vestibular schwannomas has been successful, SRS has emerged as a feasible primary treatment option for facial nerve schwannomas. ${ }^{9,11,16,19,20,27,33}$ The published studies on SRS for facial nerve schwannomas demonstrate tumor control rates and superior functional outcomes for facial nerve function and hearing comparable to those achieved with microsurgery, although the studies are few and limited by the small number of cases and short follow-up periods (Table 4). In the series reported here, tumor control was good in all 12 patients who were followed up for longer than 2 years, giving a tumor control rate of

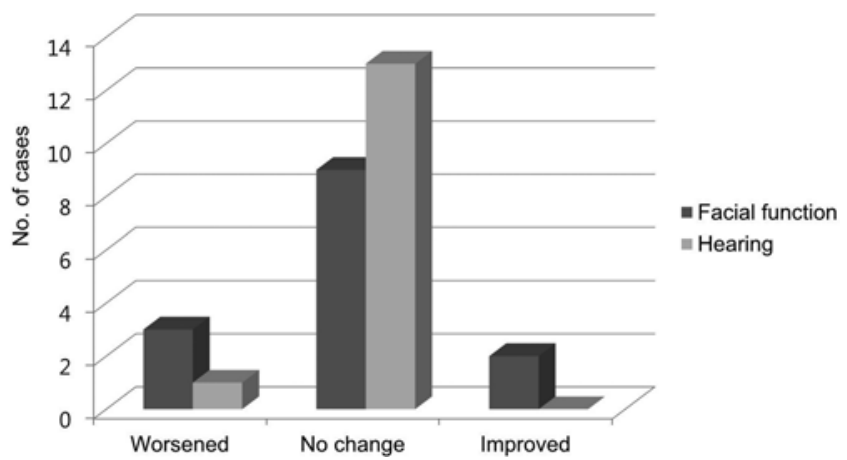

FIG. 4. Bar graph demonstrating changes in facial nerve function and hearing after GKS.
$100 \%$. A total of 9 patients have been followed up for longer than 5 years and 4 patients for longer than 10 years. The number of cases in our series is small; nevertheless, this time frame is long enough to provide reliable data on long-term tumor control. Of the 14 patients, 11 improved or maintained facial nerve function, and all patients whose hearing was serviceable at baseline maintained this level of hearing after GKS.

For 2 patients in our series, the results of improved facial nerve function were encouraging. For 1 patient, facial palsy improvement was remarkable, from HB Grade $\mathrm{V}$ to Grade II. For that patient, the facial palsy had developed abruptly 10 days before the GKS and facial nerve function returned gradually from 3 months after GKS; 1 year after the GKS, facial nerve function was nearly normal. Other than physical therapy, this patient underwent no additional surgery or other treatments for the recovery of facial nerve function. In the studies on SRS for facial nerve schwannoma, several cases demonstrated improved facial nerve function after radiosurgery; some improvement was remarkably good..$^{11,16,19}$ Unfortunately, the characteristics of those schwannomas for which facial nerve function after radiosurgery was favorable and the mechanism of recovery of facial nerve function are still unknown. We suggest that for the patient in our series for whom facial nerve function improved remarkably, the short period of facial palsy before GKS might have contributed to the recovery of facial nerve function. Gradual recovery of facial nerve function over a long period may be caused by progressive decompression resulting from shrinkage of tumor mass after GKS.

Of the 14 patients in our series, 3 (21.4\%) patients experienced deteriorated facial nerve function after GKS. In patients with vestibular schwannomas, the development of facial palsy after GKS is very rare (incidence $<1 \%$ ) even though the facial nerve is in close proximity to the neoplasm..$^{18}$ Considering that the radiosurgery range and marginal dose for vestibular schwannomas and facial nerve 
Gamma Knife surgery for facial nerve schwannomas

TABLE 4: Results after microsurgery and radiosurgery for facial nerve schwannomas reported in the literature

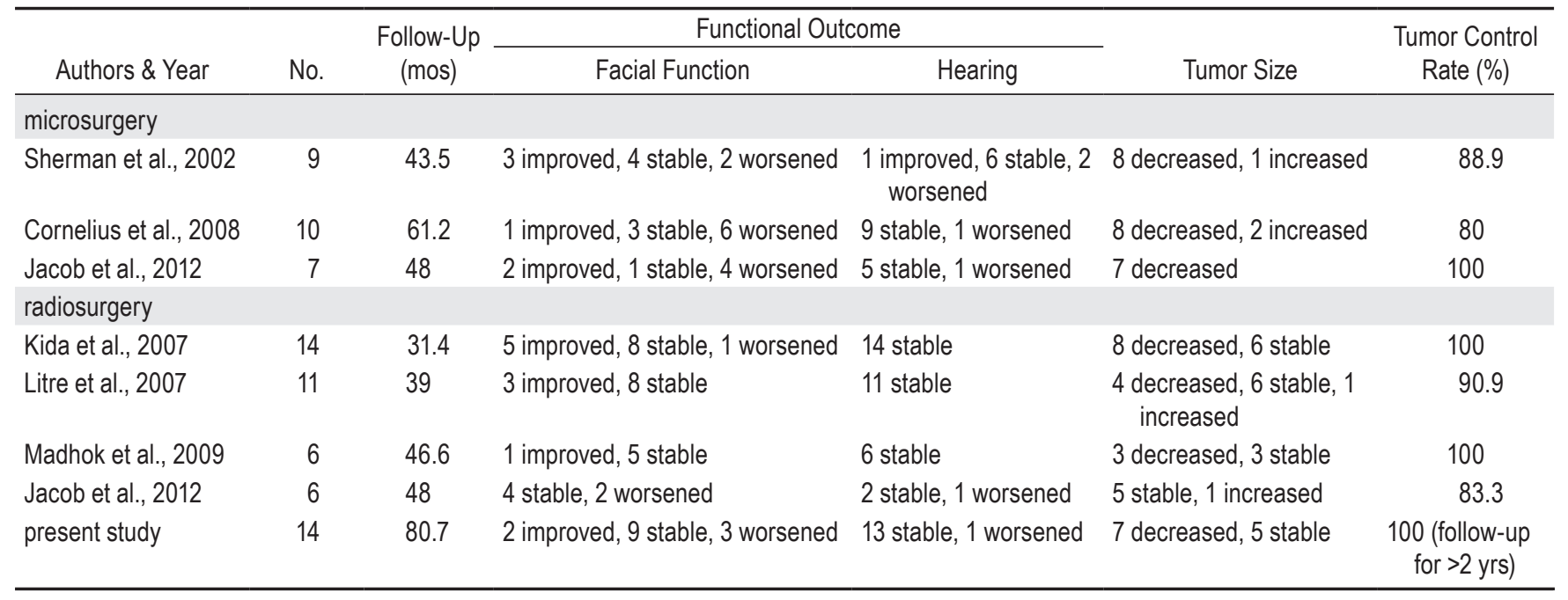

schwannomas are similar, the worsened function after GKS for facial nerve schwannoma seems aberrant. The development of facial palsy after radiosurgery for facial nerve schwannoma might result from mechanical damage to the facial nerve caused by its being pressed against the bony confinement during the temporary period of increased tumor volume (transient edema and expansion) after radiosurgery (Fig. 5). For the patients in our series, worsened facial nerve function developed within 3 months after radiosurgery, whereas the direct radiation injury of cranial nerves attributable to axonal degeneration, demyelination, and ischemia usually results in delayed (longer than 3 months) neuropathy. ${ }^{3}$ In all 3 patients who experienced deteriorated facial nerve function, the schwannomas involved the segments with bony surroundings and expanded with a loss of central enhancement on MR imaging at 6 months. Although sensory nerves are usually more sensitive to radiation than motor nerves, ${ }^{3,12}$ we observed mostly stable vestibulocochlear nerve function after radiosurgery for patients with facial nerve schwannoma. This observation indicates that the observed worsening of facial nerve function is attributable to mechanical damage rather than direct radiation injury. Therefore, use of corticosteroids to control edema and expansion during the first several months after radiosurgery might help prevent and alleviate facial palsy.

\section{Conclusions}

With this series we have shown that GKS is a relatively safe and effective management tool for both newly diagnosed and residual facial nerve schwannomas. Giv-
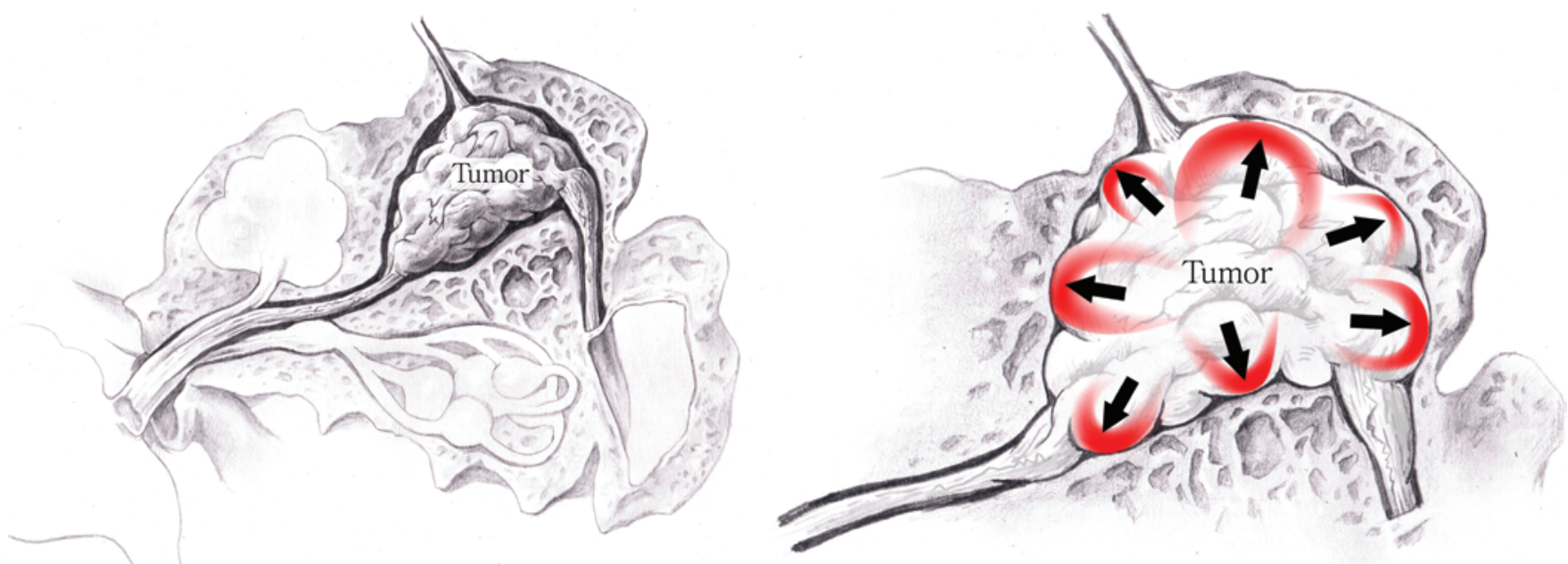

FIG. 5. Schematic diagrams illustrating the mechanism of facial nerve damage after GKS for facial nerve schwannoma. Before GKS, the facial nerve schwannoma involves the labyrinthine segment and the geniculate ganglion and is surrounded by bony structures (left). During the temporary period of increased tumor volume caused by transient postradiosurgical edema and expansion, the facial nerve is damaged by pressure against the bony confinement (right). Copyright Ju Hyung Moon. Published with permission. 
en the excellent long-term tumor control and functional outcomes, GKS might be a good primary treatment option for patients with a small- to midsized facial nerve schwannoma when facial nerve function and hearing are relatively preserved. Larger studies with longer follow-up periods are needed to define optimal radiosurgical strategies and to evaluate long-term outcomes.

\section{Disclosure}

The authors report no conflict of interest concerning the materials or methods used in this study or the findings specified in this paper.

Author contributions to the study and manuscript preparation include the following. Conception and design: JH Chang. Acquisition of data: Moon. Analysis and interpretation of data: Moon. Drafting the article: Moon. Critically revising the article: JH Chang. Reviewed submitted version of manuscript: all authors. Approved the final version of the manuscript on behalf of all authors: $\mathrm{JH}$ Chang. Administrative/technical/material support: JH Chang, WS Chang, Jung, Lee, Park. Study supervision: JH Chang.

\section{References}

1. Bacciu A, Nusier A, Lauda L, Falcioni M, Russo A, Sanna M: Are the current treatment strategies for facial nerve schwannoma appropriate also for complex cases? Audiol Neurootol 18:184-191, 2013

2. Cornelius JF, Sauvaget E, Huy PT, George B: Surgical treatment of facial nerve schwannomas. Prog Neurol Surg 21:119130,2008

3. Duma CM, Lunsford LD, Kondziolka D, Harsh GR IV, Flickinger JC: Stereotactic radiosurgery of cavernous sinus meningiomas as an addition or alternative to microsurgery. Neurosurgery 32:699-705, 1993

4. Fagan PA, Misra SN, Doust B: Facial neuroma of the cerebellopontine angle and the internal auditory canal. Laryngoscope 103:442-446, 1993

5. Falcioni M, Russo A, Taibah A, Sanna M: Facial nerve tumors. Otol Neurotol 24:942-947, 2003

6. Falcioni M, Taibah A, Russo A, Piccirillo E, Sanna M: Facial nerve grafting. Otol Neurotol 24:486-489, 2003

7. Flickinger JC, Kondziolka D, Niranjan A, Lunsford LD: Results of acoustic neuroma radiosurgery: an analysis of 5 years' experience using current methods. J Neurosurg 94:1-6, 2001

8. Hasegawa T: Stereotactic radiosurgery for nonvestibular schwannomas. Neurosurg Clin N Am 24:531-542, 2013

9. Hillman TA, Chen DA, Fuhrer R: An alternative treatment for facial nerve tumors: short-term results of radiotherapy. Ear Nose Throat J 87:574-577, 2008

10. Jacob JT, Driscoll CL, Link MJ: Facial nerve schwannomas of the cerebellopontine angle: the Mayo Clinic experience. J Neurol Surg B Skull Base 73:230-235, 2012

11. Kida Y, Yoshimoto M, Hasegawa T: Radiosurgery for facial schwannoma. J Neurosurg 106:24-29, 2007

12. Kondziolka D, Lunsford LD, Coffey RJ, Flickinger JC: Stereotactic radiosurgery of meningiomas. J Neurosurg 74:552559,1991

13. Kondziolka D, Lunsford LD, McLaughlin MR, Flickinger JC: Long-term outcomes after radiosurgery for acoustic neuromas. N Engl J Med 339:1426-1433, 1998

14. Lee JD, Kim SH, Song MH, Lee HK, Lee WS: Management of facial nerve schwannoma in patients with favorable facial function. Laryngoscope 117:1063-1068, 2007

15. Li Y, Liu H, Cheng Y: Subtotal resection of facial nerve schwannoma is not safe in the long run. Acta Otolaryngol 134:433436, 2014
16. Litre CF, Gourg GP, Tamura M, Mdarhri D, Touzani A, Roche $\mathrm{PH}$, et al: Gamma knife surgery for facial nerve schwannomas. Neurosurgery 60:853-859, 2007

17. Liu R, Fagan P: Facial nerve schwannoma: surgical excision versus conservative management. Ann Otol Rhinol Laryngol 110:1025-1029, 2001

18. Lunsford LD, Niranjan A, Flickinger JC, Maitz A, Kondziolka D: Radiosurgery of vestibular schwannomas: summary of experience in 829 cases. J Neurosurg 102 Suppl:195-199, 2005

19. Madhok R, Kondziolka D, Flickinger JC, Lunsford LD: Gamma knife radiosurgery for facial schwannomas. Neurosurgery 64:1102-1105, 2009

20. McClelland S III, Dusenbery KE, Higgins PD, Hall WA: Treatment of a facial nerve neuroma with fractionated stereotactic radiotherapy. Stereotact Funct Neurosurg 85:299-302, 2007

21. McMenomey SO, Glasscock ME III, Minor LB, Jackson CG, Strasnick B: Facial nerve neuromas presenting as acoustic tumors. Am J Otol 15:307-312, 1994

22. McMonagle B, Al-Sanosi A, Croxson G, Fagan P: Facial schwannoma: results of a large case series and review. J Laryngol Otol 122:1139-1150, 2008

23. McRackan TR, Rivas A, Wanna GB, Yoo MJ, Bennett ML, Dietrich MS, et al: Facial nerve outcomes in facial nerve schwannomas. Otol Neurotol 33:78-82, 2012 (Erratum in Otol Neurol 33:472, 2012)

24. Minovi A, Vosschulte R, Hofmann E, Draf W, Bockmühl U: Facial nerve neuroma: surgical concept and functional results. Skull Base 14:195-201, 2004

25. Mowry S, Hansen M, Gantz B: Surgical management of internal auditory canal and cerebellopontine angle facial nerve schwannoma. Otol Neurotol 33:1071-1076, 2012

26. Nadeau DP, Sataloff RT: Fascicle preservation surgery for facial nerve neuromas involving the posterior cranial fossa. Otol Neurotol 24:317-325, 2003

27. Nishioka K, Abo D, Aoyama H, Furuta Y, Onimaru R, Onodera S, et al: Stereotactic radiotherapy for intracranial nonacoustic schwannomas including facial nerve schwannoma. Int J Radiat Oncol Biol Phys 75:1415-1419, 2009

28. O'Donoghue GM, Brackmann DE, House JW, Jackler RK: Neuromas of the facial nerve. Am J Otol 10:49-54, 1989

29. Perez R, Chen JM, Nedzelski JM: Intratemporal facial nerve schwannoma: a management dilemma. Otol Neurotol 26:121126,2005

30. Pollock BE, Foote RL, Stafford SL: Stereotactic radiosurgery: the preferred management for patients with nonvestibular schwannomas? Int J Radiat Oncol Biol Phys 52:1002-1007, 2002

31. Sherman JD, Dagnew E, Pensak ML, van Loveren HR, Tew JM Jr: Facial nerve neuromas: report of 10 cases and review of the literature. Neurosurgery 50:450-456, 2002

32. Symon L, Cheesman AD, Kawauchi M, Bordi L: Neuromas of the facial nerve: a report of 12 cases. Br J Neurosurg 7:13-22, 1993

33. Wilkinson EP, Hoa M, Slattery WH III, Fayad JN, Friedman RA, Schwartz MS, et al: Evolution in the management of facial nerve schwannoma. Laryngoscope 121:2065-2074, 2011

Manuscript submitted June 30, 2014.

Accepted August 4, 2014.

Please include this information when citing this paper: DOI: 10.3171/2014.8.GKS141504.

Address correspondence to: Jong Hee Chang, M.D., Ph.D., Department of Neurosurgery, Yonsei University Health System, 50-1 Yonsei-ro, Seodaemun-gu, Seoul 120-752, Republic of Korea. email: changjh@yuhs.ac. 